FACTA UNIVERSITATIS

Series: Mechanical Engineering Vol. 15, Nº 2, 2017, pp. 341 - 351

DOI: 10.22190/FUME170419017J

Original scientific paper

\title{
ALTERNATIVE METHOD FOR ON SITE EVALUATION OF THERMAL TRANSMITTANCE
}

\author{
UDC 691
}

\author{
Aleksandar Janković, Biljana Antunović, Ljubiša Preradović \\ Faculty of Architecture, Civil Engineering and Geodesy, University of Banja Luka, \\ Bosnia and Herzegovina
}

\begin{abstract}
Thermal transmittance or U-value is an indicator of the building envelope thermal properties and a key parameter for evaluation of heat losses through the building elements due to heat transmission. It can be determined by calculation based on thermal characteristics of the building element layers. However, this value does not take into account the effects of irregularities and degradation of certain elements of the envelope caused by aging, which may lead to errors in calculation of the heat losses. An effective and simple method for determination of thermal transmittance is in situ measurement, which is governed by the ISO 9869-1:2014 that defines heat flow meter method. This relatively expensive method leaves marks and damages surface of the building element. Furthermore, the final result is not always reliable, in particular when the building element is light or when the weather conditions are not suitable. In order to avoid the above mentioned problems and to estimate the real thermal transmittance value an alternative experimental method, here referred as the natural convection and radiation method, is proposed in this paper. For determination of thermal transmittance, this method requires only temperatures of inside and outside air, as well as the inner wall surface temperature. A detailed statistical analysis, performed by the software package SPSS ver. 20, shows several more advantages of this method comparing to the standard heat flow meter one, besides economic and non-destructive benefits.
\end{abstract}

Key Words: Thermal Transmittance, Heat Flow Meter Method, Natural Convection and Radiation Method, Software Support, Statistical Analysis

Received April 19, 2017 / Accepted July 03, 2017

Corresponding author: Aleksandar Janković

University of Banja Luka, Faculty of Architecture, Civil Engineering and Geodesy,

Vojvode Stepe Stepanovića 77/3, 78000 Banja Luka, Bosnia and Herzegovina

E-mail: aleksandar.jankovic@aggf.unibl.org 


\section{INTRODUCTION}

Building envelope represents the boundary between the inner and the outer space with the purpose to protect building occupants from different atmospheric conditions. Its function is to provide a comfortable and healthy environment to the building users with its hygrothermal characteristics which are determined by the structure, adequate selection and order of used materials [1]. In modern society heat loss through the building envelope represents a significant share of the total energy consumption of the facility. Therefore, the aim is to reduce heat loss, increase energy efficiency of buildings and achieve an optimal thermal comfort for its occupants. Thermal performance of the building envelope is primarily determined by thermal transmittance or U-value $\left[\mathrm{W} \cdot \mathrm{m}^{-2} \mathrm{~K}^{-1}\right]$. This quantity is the starting point for calculating energy consumption for heating and cooling of the building as well as its maintenance cost.

For existing buildings and especially for buildings in the design phase the thermal transmittance of the envelope is determined by calculation based on the thermal characteristics of the structural elements. However, this value does not take into account the effects of irregularities and degradation of certain envelope elements caused by aging which may lead to a difference between the theoretical and the actual values [2]. Therefore, it is essential to measure on site thermal transmittance in the real conditions in order to minimize errors in the estimation of heat losses through the building envelope. One simple and effective method for determining actual thermal transmittance through the building element involves measuring the heat flux density at the same time with the inside and the outside air temperature. This insitu measurement is governed by the ISO 9869-1:2014 that defines the heat flow meter method or HFM method [3]. The sensor that measures the temperature of the outside air should not be exposed to direct solar radiation and precipitation. Therefore, the final result is not always reliable, in particular when the building element is light (low specific heat of materials) and if multi-layered air spaces are present (even if slowly ventilated) [4].

In the last few years, new techniques have been proposed for in situ determination of thermal transmittance of the building elements. Several researchers have proposed the use of quantitative thermography for a rapid in situ measurement of the overall transmittance of an envelope building in a short time [4]. Albatici and Tonelli [5, 6] use a technique that involves parameters measured by infrared thermography, except for the wind velocity which is measured by a hot-wire anemometer in proximity of the wall. Differences with U-values determined by the HFM are of the order of $30 \%$, while differences with calculated U-values can grow up to $80 \%$. Grinzato et al. [7] proposed a more rigorous and complex procedure involving a light metallic frame useful for accurate measurements of wall and air temperatures thus consequently getting more precise thermal transmittance evaluation. Reported experimental results show a difference with U-values determined by the HFM of the order of $30-35 \%$. For a quite long time several other methods that do not involve infrared thermography have been in use for experimental determination of thermal transmittance of the building elements, like hot box method $[8,9]$ or the temperature based method [10]. The hot box method is mainly used for thermal transmittance measurements of inhomogeneous components such as windows, doors and thermal bridges in laboratory and cannot be used for in situ measurements. It is a very reliable method, if the detailed and precise calibration procedure is complied [11]. The temperature based method lacks accuracy, but it is often used in practice, where the heat flux is approximated by measuring the inside 
temperature and the wall temperature assuming constant inner thermal boundary resistance. Recently, a rapid in-situ measurement of the wall's thermal resistance and U value by the Excitation Pulse Method is developed at Delft University of Technology [12].

None of these techniques, except the heat box one, were standardized because they did not meet the balance between convenience and accuracy offered by the HFM method. Some of them offer practicality but lack accuracy and vice versa. In accordance with the modern trends and with the aim to avoid the problems of the HFM method, a new experimental methodology based on the measuring inside and outside air temperature and the inner wall surface temperature is proposed in this paper. This new experimental method hereinafter will be referred to as the $\mathrm{NCaR}$ method (natural convection and radiation method).

\section{THERMAL TRANSMITTANCE}

For plane, opaque and homogenous building elements thermal transmittance $U$ can be determined by calculation based on the thermal characteristics of the consisting materials according to the formula [13]:

$$
U=\frac{1}{\frac{1}{\alpha_{i}}+\sum_{k=1}^{n} \frac{l_{k}}{\lambda_{k}}+\frac{1}{\alpha_{e}}}
$$

where $l_{k}$ and $\lambda_{k}$ represent thickness and thermal conductivity of $\mathrm{k}$-th layer of building element, respectively, while $1 / \alpha_{i}$ and $1 / \alpha_{s}$ denote the inner and outer resistances of the building element to heat transfer, respectively. This method refers to the dominant one dimensional heat transfer, such as the flat walls of the building envelope. In order to obtain representative values of the thermal transmittance it is necessary to comply with certain practical rules during measurement.

The thermal transmittance determination by the heat flowmeter method is based on some simplifying hypotheses. In selecting the measuring point the thermal bridges and the construction joints with dominant two-dimensional and three-dimensional heat transfer have to be avoided. The sensor intended to measure the temperature of the outside air should not be exposed to the direct solar radiation and precipitation. The maximum time period between two records and the minimum test duration depends on: the nature of the element, indoor and outdoor temperatures and the method used for analysis. Two methods may be used for analysis of the data in accordance with the ISO 9869-1: the so-called average method, which is simple, or the dynamic method, which is more sophisticated but which gives quality criteria of the measurement and may shorten the test duration for medium to heavy elements submitted to variable indoor and outdoor temperatures. During the test the minimum difference between the inner and the outer air temperatures has to reach $10-15{ }^{\circ} \mathrm{C}$. Average method assumes that the thermal transmittance can be obtained by dividing the mean density of heat flow rate $q$ by the mean difference between the inside and outside air temperatures, $T_{i}$ and $T_{e}$ respectively, according to the formula [3]: 


$$
U=\frac{\sum_{j} q_{j}}{\sum_{j}\left(T_{i}-T_{e}\right)_{j}}
$$

where index $j$ enumerates the individual measurements. For heavier elements, which have a specific heat per unit area of more than $20 \mathrm{~kJ} \cdot \mathrm{m}^{-2} \mathrm{~K}^{-1}$, the analysis shall be carried out over a period which is an integer multiple of $24 \mathrm{~h}$. The test shall end only when the duration of the test exceeds $72 \mathrm{~h}$, the thermal resistance value obtained at the end of the test does not deviate by more than $\pm 5 \%$ from the value obtained $24 \mathrm{~h}$ before and the change in heat stored in the wall is less than $5 \%$ of the heat passing through the wall over the test period. Also, the thermal resistance obtained by analyzing the data from the first time period during INT $\left(2 \times D_{T} / 3\right)$ shall not deviate by more than $\pm 5 \%$ from the values obtained from the data of the last time period of the same duration, whereby $D_{T}$ is the duration of the test in days and INT denotes the integer part of a number. With such strict criteria and due to a great number of limitations in-situ measurement of thermal transmittance with heat flowmeter method is not always possible.

The heat transfer between the inside air and the inner wall surface are affected by several transport mechanisms: heat conduction through the air adjacent to the surface, convective transport by air flows, and emission of long-wave radiation. Since the conduction is negligible due to the very low thermal conductivity of the air, the heat transfer is largely controlled by the other two mechanisms that are described by quantity called the heat transfer coefficient [14]:

$$
\alpha=\alpha_{r}+\alpha_{c}
$$

where $\alpha_{r}$ and $\alpha_{c}$ are the coefficients that indicate the contribution to the heat transfer by radiation and convection, respectively.

The convective heat transfer from the inside air to the inner wall surface happens due to the fluid motion, which is not generated by external force, but only by temperature gradients in fluid itself. This type of the heat transfer is also known as the natural convection. This assumption is valid only for the air inside the room, namely, the room which is not mechanically ventilated or air conditioned; it does not apply to the outside air, where the convective heat transfer is forced by an externally induced flow (wind). The convective heat transfer between the solid surface and the fluid in contact is described by a quantity called the convective heat transfer coefficient. There are various equations for the convective heat transfer coefficient expressed as the function of the temperature difference between the surface temperature and the temperature of the air out of the thermo-kinetic boundary layer (undisturbed air) [14]:

$$
\alpha_{c}=C \cdot\left(T_{i}-T_{i s}\right)^{n}
$$

where $C$ and $n$ represent constants and $T_{i s}$ is the temperature of the wall surface. The equations resulting from various choices of parameters $C$ and $n$ are represented in Table 1 together with the names of the authors who studied the natural convection and derived the corresponding values of the parameters. Table 1 also includes the standard method for quantifying the convective heat transfer coefficient proposed by the American Society of Heating, Refrigerating and Air-Conditioning Engineers (ASHRAE). 
Table 1 The convective heat transfer coefficients in the case of the natural convection [14]

\begin{tabular}{lc}
\hline Author(s) & $\alpha_{c}\left[\mathrm{~W} \cdot \mathrm{m}^{-2} \mathrm{~K}^{-1}\right]$ \\
\hline Awbi et al. [15] & $1.49 \cdot \Delta t^{0.345}$ \\
Khalifa et al. [16] & $2.07 \cdot \Delta t^{0.23}$ \\
Michejev [17] & $1.55 \cdot \Delta t^{0.33}$ \\
King [18] & $1.51 \cdot \Delta t^{0.33}$ \\
Nusselt [19] & $2.56 \cdot \Delta t^{0.25}$ \\
Heilman [20] & $1.67 \cdot \Delta t^{0.27}$ \\
Wilkers et al. [21] & $3.04 \cdot \Delta t^{0.12}$ \\
ASHRAE [22] & $1.31 \cdot \Delta t^{0.33}$ \\
\hline
\end{tabular}

A wall surface always exchanges long-wave thermal radiation with other surfaces in its surroundings. The corresponding heat flow depends on the temperatures (to the fourth power), the material properties and the nature of the surfaces. The radiative heat transfer from the inside air to the inner wall surface is described by a quantity called the radiative heat transfer coefficient [23]:

$$
\alpha_{r}=\varepsilon \cdot \sigma \frac{\left(T_{i}^{4}-T_{i s}^{4}\right)}{T_{i}-T_{i s}}
$$

where $\varepsilon$ represents the emissivity of the wall surface and $\sigma=5.67 \cdot 10^{-8} \mathrm{~W} \cdot \mathrm{m}^{-2} \mathrm{~K}^{-4}$ is the Stefan-Boltzmann constant.

If we assume stationary conditions in which the heat flux density through the wall is equal to the heat flux density that is transferred from the indoor air to the inner wall surface, then the thermal transmittance of the wall can be determined from the known values of the heat transfer coefficient and directly measured temperatures:

$$
U=\alpha \frac{\left(T_{i}-T_{i s}\right)}{\left(T_{i}-T_{e}\right)}
$$

Finally, the thermal transmittance of the wall can be determined if we consider the heat transfer from the surrounding air to the inner wall surface that occurs through the natural convection and radiation, according to the following formula:

$$
U=\frac{C \cdot\left(T_{i}-T_{i s}\right)^{n+1}+\varepsilon \cdot \sigma \cdot\left(T_{i}^{4}-T_{i s}^{4}\right)}{\left(T_{i}-T_{e}\right)}
$$

This alternative method, named the NCaR method, is based on the measured temperatures of the inside and the outside air and the inside wall surface temperature, as well as emissivity of the inner wall surface. The method requires continuous monitoring of temperatures with the same recording interval as the HFM method. Taking into account individual measurements (enumerated with index $j$ ), the thermal transmittance can be obtained by the following equation:

$$
U=\frac{C \cdot \sum_{j}\left(T_{i}-T_{i s}\right)_{j}^{n+1}+\varepsilon \cdot \sigma \cdot \sum_{j}\left(T_{i}^{4}-T_{i s}^{4}\right)_{j}}{\sum_{j}\left(T_{i}-T_{e}\right)_{j}}
$$




\section{MeAsurement Methodology}

Testo 435-2 data logger with appropriate sensors was used to measure the heat flux density and the corresponding inside and outside air temperatures necessary for determining thermal transmittance of the wall by the HFM method. On the other side, Ahlborn Almemo 2690 data logger with K-type thermocouples sensors for air temperatures and a film sensor for surface temperature of the wall was used for determining thermal transmittance of the wall by the NCaR method. Measurements were made on the northern wall of the preschool building. The structure and possible thermal characteristics of the tested wall are shown in Table 2. The project documentation indicates that the wall was built from the hollow bricks plastered on both sides with the layer of lime cement mortar, but there is no specific information about thermal characteristics of the used materials. Two types of hollow bricks were used $\left(0.52\right.$ and $\left.0.61 \mathrm{Wm}^{-1} \mathrm{~K}^{-1}\right)$ during considered construction period, as well as various types of the lime cement mortar $\left(0.85-0.99 \mathrm{Wm}^{-1} \mathrm{~K}^{-1}\right)$. Therefore, the range of the possible thermal transmittance values $\left(1.241-1.404 \mathrm{Wm}^{-2} \mathrm{~K}^{-1}\right)$ is derived. Based on the type of construction, it can be concluded that it is a heavier type of building element characterized by specific heat capacity per unit area greater than $20 \mathrm{~kJ} \cdot \mathrm{m}^{-2} \mathrm{~K}^{-1}$.

Table 2 Thermal characteristics of the wall

\begin{tabular}{lccrc}
\hline Layers & Thickness $[\mathrm{cm}]$ & $\begin{array}{c}\text { Thermal } \\
\text { conductivity } \\
{\left[\mathrm{Wm}^{-1} \mathrm{~K}^{-1}\right]}\end{array}$ & $\begin{array}{c}\text { Thermal } \\
\text { resistance } \\
{\left[\mathrm{m}^{2} \mathrm{KW}^{-1}\right]}\end{array}$ & $\begin{array}{c}\text { Thermal } \\
\text { transmittance } \\
{\left[\mathrm{Wm}^{-2} \mathrm{~K}^{-1}\right]}\end{array}$ \\
\hline Inside air & 2 & $0.85-0.99$ & $0.024-0.020$ \\
Inner lime-cement plaster & 30 & $0.52-0.61$ & $0.577-0.492$ \\
Hollow brick & 3 & $0.85-0.99$ & $0.035-0.020$ & \\
Exterior lime-cement plaster & & & 0.040 & \\
Outside air & & & $0.806-0.712$ & $1.241-1.404$ \\
\hline Total & & & & \\
\hline
\end{tabular}

In order to obtain representative measurements the thermal bridges and the construction joints are avoided as well as the direct influence of heating and cooling devices. The sensor for heat flux density was mounted on the inner surface of the wall, in the area of the uniform temperature field, which was determined by the thermal imager. The thermal contact paste is applied in order to provide direct contact with the element over entire surface of the heat flowmeter. The sensors for the inner wall surface and the inside air temperatures were mounted under and in the vicinity of the heat flowmeter, while the sensor for the outside air temperature was mounted on the opposite side of the wall of the heat flowmeter.

During the measurement, the sensor for the outside temperature has not been exposed to the direct solar radiation and precipitation. Considering the fact that stable temperature was achieved around the heat flowmeter and inside the temperature sensors, the test duration lasted $72 \mathrm{~h}$ with recording interval of 15 minutes.

The inside and the outside air temperatures and the heat flux density measured by the Testo 435-2 instrument were used to determine thermal transmittance by the HFM method. Inside air, the inner wall surface and the outside air temperatures measured by the Almemo Ahlborn 2690-8 instrument were used to determine the thermal transmittance by the NCaR method. This method also required determining emissivity of the inner wall surface, which 
was carried out by the thermal imager. The emissivity displayed on the thermal imager had been adjusted to the real value, in such way that the temperature value shown on the thermal image was the same as the actual temperature of the inner wall surface measured by the film sensor [24]. If there is no thermal imager available during measurements, the emissivity can be assumed if the type of material is known since some materials have well known and standardized values. After the measurement is completed, the temperature sensors which served for determining U-value by the NCaR method have not left marks on inner wall surface. On the contrary, because of the applied thermal paste, the plate for measuring the heat flux chopped off thin layer of plaster from the inner wall surface.

\section{RESULTS}

The measurement period includes full days from Feb., 10, 2015 to Feb, 13, 2015, which is longer than the required minimum time interval demanded by the ISO 9869-1:2014. The weather favored the measurements and the temperature difference between the inside and the outside air was at least $10{ }^{\circ} \mathrm{C}$. Fig. 1 shows the temporal evolution of the weather conditions, where the indoor and the outdoor temperatures are marked with the green and purple color, respectively, and the inner wall surface temperature is marked with the blue color. For emissivity of the inner wall surface the value of 0.91 was obtained.

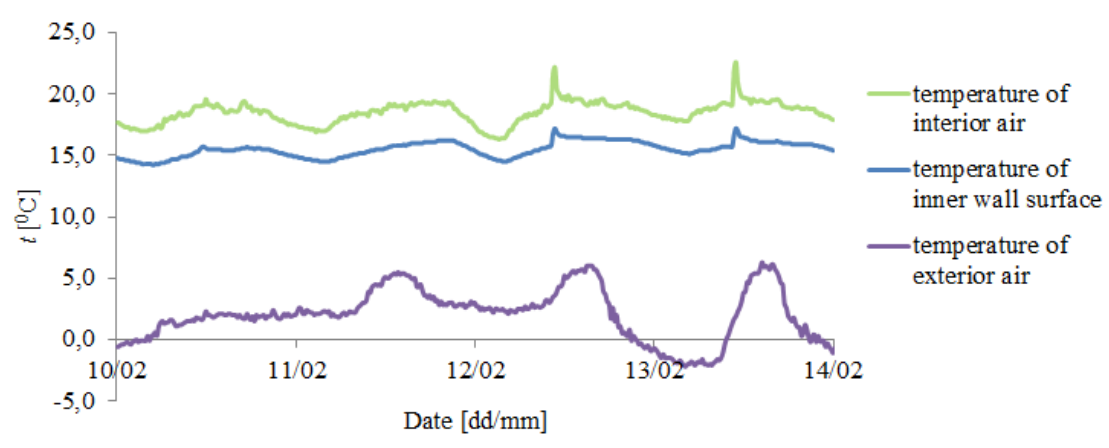

Fig. 1 The temporal evolution of inside and outside temperatures

The analysis of the measurement results are performed by the average method. The thermal resistance value obtained by the HFM method at the end of the test period deviates $-4.78 \%$ from the value obtained $24 \mathrm{~h}$ earlier, while the same comparison for the $\mathrm{NCaR}$ method shows deviation of $0.60 \%$. The thermal resistance obtained by analyzing the data for the time period covering first two days deviates $-2.52 \%$ (for the NCaR method) and $-4.75 \%$ (for the HFM method) from the values obtained for the time period covering the last two days. It is obvious that $\mathrm{NCaR}$ method shows better agreement of the thermal resistance values obtained from different periods within the measuring interval. Table 3 shows the average values of thermal transmittance obtained by the HFM and different NCaR methods, according to the relations (2) and (7), respectively. The results from different $\mathrm{NCaR}$ methods are represented depending on the numerical values of $\mathrm{C}$ and $\mathrm{n}$ constants derived from the expression for the convective heat transfer coefficient. 
The third value is the theoretical thermal transmittance calculated based on the thermal characteristics of the materials which constitute the building element that was analyzed.

Table 3 The overall thermal transmittance measured by HFM and NCaR methods

\begin{tabular}{llrr}
\hline & & $\begin{array}{c}U \\
{\left[\mathrm{Wm}^{-2} \mathrm{~K}^{-1}\right]}\end{array}$ & $\begin{array}{c}\text { Deviation } \\
\text { from HFM } \\
{[\%]}\end{array}$ \\
\hline HFM method & & 1.210 & - \\
\hline & ASHRAE [22] & 1.268 & 4.82 \\
& Awbi et al. [15] & 1.322 & 9.29 \\
& Khalifa et al. [16] & 1.411 & 16.64 \\
NCaR method & 1.332 & 10.05 \\
& Michejev [17] & 1.321 & 9.18 \\
& King [18] & 1.540 & 27.31 \\
& Nusselt [19] & 1.335 & 10.32 \\
& Heilman [20] & 1.558 & 28.76 \\
\hline Theoretical & Wilkers [22] & $1.241-1.404$ & $2.56-16.03$ \\
\hline
\end{tabular}

As can be seen from Table 3, the mean U-value obtained using the NCaR method, derived from the ASHRAE equations for the convective heat transfer coefficient, has the best agreement (the smallest deviation) with the mean U-value obtained by the HFM method. Furthermore, it can be concluded that the HFM method and the ASHRAE NCaR method are highly correlated. The correlation coefficient between the measurements obtained by the ASHRAE NCaR and HFM method is very high and amounts to 0.956 .

Table 4 Detailed comparison of HFM and NCaR methods

\begin{tabular}{llll}
\hline & HFM & NCaR & HFM cf. NCaR \\
\hline Standard deviation $\left[\mathrm{Wm}^{-2} \mathrm{~K}^{-1}\right]$ & 0.280 & 0.252 & 0.102 \\
Mean absolute deviation $\left[\mathrm{Wm}^{-2} \mathrm{~K}^{-1}\right]$ & 0.234 & 0.213 & 0.083 \\
Mean absolute percentage deviation [\%] & 19.3 & 16.8 & 6.5 \\
\hline
\end{tabular}

Further statistical comparison performed by the software package SPSS ver. 2.0 shows a high agreement between two methods with a relatively small standard, mean absolute and average relative deviation (tab. 4). The $\mathrm{NCaR}$ method indicates smaller dispersion of measurements around the mean than the HFM method, which is confirmed by the lower values of standard, mean absolute and mean relative deviation (tab. 4). This is also noticeable from Fig. 2, where the changes of the thermal transmittance measured by the NCaR method are more dumped, which indicates that this method is less sensitive to the measurement conditions [25]. The lower standard deviation around the mean value of the NCaR method indicates a better experimental technique as well as more precise and reliable measurements than the HFM method. Furthermore, the U-value obtained by the $\mathrm{NCaR}$ method agrees with assumed interval of the theoretical U-value, unlike the thermal transmittance obtained by the HFM method. 


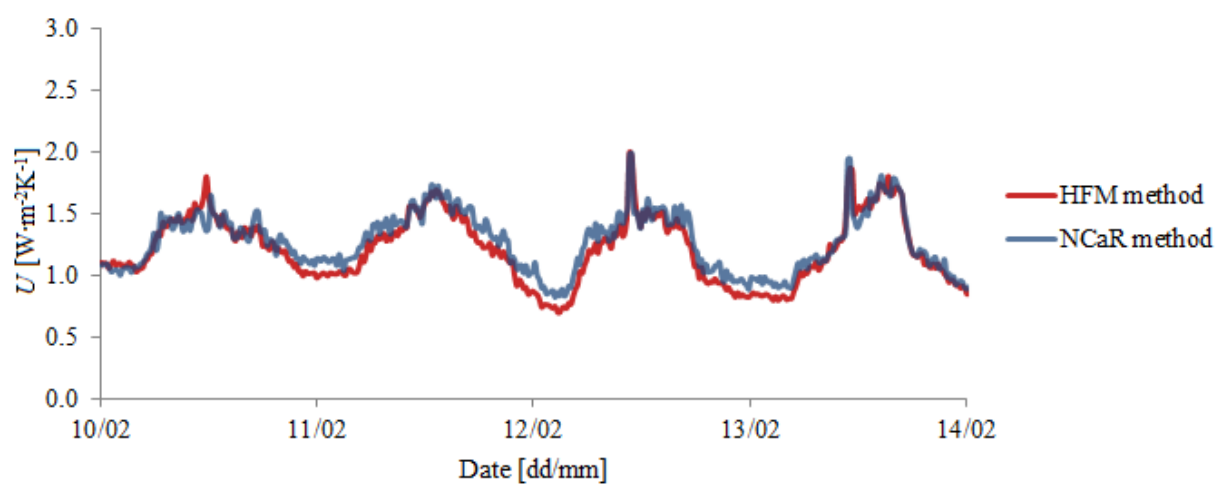

Fig. 2 The temporal evolution of the thermal transmittance measured by the HFM (red) and the NCaR (blue) method

\section{CONCLUSIONS}

The measurement of the $\mathrm{U}$-value based on the $\mathrm{NCaR}$ method has three main and meaningful advantages in comparison to the HFM method:

1) The temperature sensors do not leave marks or damage the surface on a building element, as it happens with the plates for measuring the heat flux density in the HFM method.

2) The measurement procedure can be performed with the temperature data loggers, which are considerably cheaper than the instruments for determining thermal transmittance by measuring heat flux density.

3) This method could be used to measure the thermal transmittance of the light building elements, as the sensors for measuring temperature do not significantly modify the heat flow and temperature field on the surface of a building element in contrast to the standard sensors for heat flux density.

The NCaR method shows fewer damped oscillations of the U-value in comparison with the HFM method, which leads to the conclusion that this method is less sensitive to the measurement conditions and that the obtained data is more reliable and precise. The main limitations of the NCaR method are the same as main limitations as the HFM method, which also assumes stationary conditions and natural convection as the only type of the convective heat transfer from the indoor air to the inner wall surface:

1) This method requires calm conditions. The air conditioners and fans should not be powered on during the measurement and the room may be just slightly naturally ventilated. In this way occurrence of the forced convection is avoided.

2) Since the heat flow is not constant, the minimum duration of the test should be $72 \mathrm{~h}$ long and the minimum temperature difference between the inside and the outside air must be at least $10{ }^{\circ} \mathrm{C}$.

The measured U-values by two given methods are in a very good agreement, which means that presented the NCaR method is equally reliable as the standard HFM method. Taking into account the above mentioned advantages, it can be also concluded that the $\mathrm{NCaR}$ method is significantly simpler and cheaper than the HFM one. However, the 
proposed method needs further testing on different types of building elements in different conditions in order to draw more profound conclusions about the method reliability and applicability. The authors think that, if the measurement of the thermal transmittance is carried out in a proper manner following the procedure described in this paper by a technician with specific knowledge of building physics, the final result of the test can be just as reliable as the one made with the heat flow meter method.

\section{REFERENCES}

1. Antunović, B., Janković, A., Preradović, Lj., 2014, Thermal performance of preschool education building envelope, Proceedings of International Conference Contemporary Achievements in Civil Engineering, Subotica, Serbia, pp. 545-550.

2. Antunović, B., Stanković, M., Janković, A., Gajić, D., Todorović, D., 2012, Measurement of thermal transmittance in the Rectorate building of the University of Banja Luka, Proceedings of International Scientific Conference Contemporary Theory and Practice in Civil Engineering, Banja Luka, Bosnia and Herzegovina, pp. $37-46$.

3. ISO 9869:2014-1, Thermal Insulation - Building elements - In-situ measurement of thermal resistance and thermal transmittance, International Organization for Standardization, Geneva, Switzerland.

4. Nardi, I., Sfarra, S., Ambrosini, D., 2014, Quantitative thermography for the estimation of the U-value: state of the art and a case study, Journal of Physics: Conference Series, 547(1), DOI: 10.1088/1742-6596/547/1/012016.

5. Albatici, R, Tonelli, A.M., 2010, Infrared thermovision technique for the assessment of thermal transmittance value of opaque building elements on site, Energy and Buildings, 42(11), pp. 2177-2183.

6. Albatici, R., Tonelli, A.M., Chiognac, M., 2015, A comprehensive experimental approach for the validation of quantitative infrared thermography in the evaluation of building thermal transmittance, Applied Energy, 141, pp. 218-228

7. Grinzato, E., Bison, P., Cadelano, G., Peron, F., 2010, R-value estimation by local thermographic analysis Proceedings of Thermosense XXXII, Orlando, USA, doi:10.1117/12.850729.

8. ISO 12567-1:2010, Thermal performance of windows and doors - Determination of thermal transmittance by the hot-box method - Part 1: Complete windows and doors, International Organization for Standardization, Geneva, Switzerland.

9. ISO 12567-2:2005, Thermal performance of windows and doors - Determination of thermal transmittance by the hot box method - Part 2: Roof windows and other projecting windows, International Organization for Standardization, Geneva, Switzerland.

10. Cucumo, M., De Rosa, A., Ferraro, V., Kaliakatsos, D., Marinelli, V., 2006, A method for the experimental evaluation in situ of the wall conductance, Energy and Buildings, 38(3), pp. 238-244.

11. Asdrubali, F., Baldinelli, G., 2011, Thermal transmittance measurements with the hot box method: Calibration, experimental procedures, and uncertainty analyses of three different approaches, Energy and Buildings, 43(7), pp. 1618-1626.

12. Rasooli, A., Itard, L., Ferreira, C.I., 2016, A response factor-based method for the rapid in situ determination of wall's thermal resistance in existing buildings, Energy and Buildings, 119, pp. 51- 61.

13. Schild, K., Willems, V.M., 2006, Building Physics - Handbook - part 1, Friedrich Vieweg \& Sohn Verlag, Wiesbaden, Germany, 2.21.

14. Min, T.C., Schutrum, L.F., Parmelee, G.V., Vouris, J.D., 1956, Natural convection and radiation in a panel heated room, Heating Piping and Air Conditioning (HPAC), 62, pp. 337-358.

15. Awbi, H.B., Hatton, A., 1999, Natural convection from heated room surfaces, Energy and Buildings, 30, pp. 234- 244.

16. Khalifa, A.J.N., Marshall R.H., 1990, Validation of heat transfer coefficients on interior building surfaces using a real-sized indoor test cell, International Journal of Heat and Mass Transfer, 33, pp. 2219-2236.

17. Michejev, M. A., 1952, Základy sdílení tepla, Průmyslové vydavatel'ství, Prague, Czechoslovakia, p. 387.

18. King, W., 1932, The basic laws and data of heat transmission, Mechanical Engineering, 54, pp. 347-353.

19. Nusselt, W., 1915, Das Grundgesetz des Wärmeüberganges, Gesundheits-Ingenieur, 38(42), pp. 477-482.

20. Heilman, R.H., 1929, Surface heat transmission, Mechanical Engineering, 51, p. 355.

21. Wilkers, G.B., Peterson, C.M.F., 1938, Radiation and convection from surfaces in various positions, ASHVE Transactions, 44, p. 513. 
22. ASHRAE (American Society of Heating, Refrigerating and Air-conditioning Engineer), 2001, ASHRAE Handbook, Fundamentals, American Society of Heating, Refrigerating and Air-conditioning Engineers, Atlanta, USA.

23. Hens, H., 2007, Building Physics - Heat, Air and Moisture, Enrst \& Son, Berlin, Germany, 73 pp.

24. Binachi, F., Baldinelli, G., Asdrubali, F., 2014, A quantitative infrared thermography method for the assessment of windows thermal transmittance, Proceedings of Latest Trends in Applied and Theoretical Mechanics, Salerno, Italy, pp. $137-143$.

25. Antunović, B., Janković, A., Preradović, Lj., 2015, Measurement of thermal transmittance of opaque facade wall and relationship with meteorological conditions, Tehnika, 70(4), pp. 593 - 598. 